\title{
Aggrecan structure in amphibian cartilage
}

D.Z. Covizi $i^{1,2}$ and H.F. Carvalho ${ }^{1}$

\author{
Departamentos de ${ }^{1}$ Biologia Celular and \\ 2Bioquímica, Universidade Estadual de Campinas, \\ Campinas, SP, Brasil
}

\section{Correspondence \\ H.F. Carvalho \\ Departamento de Biologia Celular UNICAMP \\ Caixa Postal 6109 \\ 13083-970 Campinas, SP \\ Brasil \\ Fax: + 55-19-788-7821 \\ E-mail: hern@ unicamp.br}

Research supported by FAPESP (Nos. 95/6683-2, 95/6684-9, and $97 / 4925-4)$ and $\mathrm{CNPq}$ (No. 520582/95-0).

Received December 22, 1999 Accepted September 14, 2000

\section{Abstract}

The structure of the large proteoglycan present in the bullfrog epiphyseal cartilage was studied by immunochemical and biochemical methods. The isolated monomer showed a polydisperse behavior on Sepharose $\mathrm{CL} 2 \mathrm{~B}$, with a peak at $\mathrm{Kav}=0.14$. Chondroitin sulfate chains were identified by HPLC analysis of the products formed by chondroitinase digestion and mercuric acetate treatment. These chains have approximately 38 disaccharides, a Di45:Di68 ratio of 1.6 and GalNAc4S + GalNAc4,6S are the main non-reducing terminals. Keratan sulfate was identified by the use of two monoclonal antibodies in Western blots after chondroitinase $\mathrm{ABC}$ treatment. A keratan sulfate-rich region $(\sim 110 \mathrm{kDa})$ was isolated by sequential treatment with chondroitinase $\mathrm{ABC}$ and proteases. We also employed antibodies in Western blotting experiments and showed that the full length deglycosylated core protein is about $300 \mathrm{kDa}$ after SDS-PAGE. Domain-specific antibodies revealed the presence of immunoreactive sites corresponding to $\mathrm{G} 1 / \mathrm{G} 2$ and $\mathrm{G} 3$ globular domains and the characterization of this large proteoglycan as aggrecan. The results indicate the high conservation of the aggrecan domain structure in this lower vertebrate.
Key words

- Aggrecan

- Bullfrog

- Cartilage

- Chondroitin sulfate

- Epiphyseal cartilage

\section{Introduction}

Cartilage is a resilient tissue able to resist tension and pressure forces (1). These properties are thought to result from a highly coordinated array of various components, amongst which are type II collagen, large and small proteoglycans, and other non-collagenous glycoproteins $(2,3)$. The large proteoglycan aggrecan consists of a core protein to which the glycosaminoglycans (GAGs) chondroitin sulfate (CS) and keratan sulfate (KS) and N- and O-linked oligosaccharides are attached (4). The GAGs have a high negative fixed-charge density, conferring on aggrecan its characteristic osmotic activity (5) which, in addition to the capacity to aggregate with hyaluronan and participate in a concerted interplay with type II collagen fibrils, endows the tissue with the ability to withstand compressive forces and to distribute the load (6).

The aggrecan core protein has different domains (Figure 1). The G1 domain at the Nterminal consists of three subdomains and binds to hyaluronan and link protein in huge aggregate structures (7-9). The interglobular domain, located between the G1 and G2 
Figure 1 - Schematic drawing of the aggrecan core protein $(A)$ and the sites of reactivity of the different antibodies employed in the present study. G1 and G2 are $21 \mathrm{~nm}$ apart from each other. Between G2 and G3 are the keratan sulfate (KS)-rich region and the chondroitin sulfate (CS) substitution region. The antiATEGQV antibody reacts with a peptide present in G1. The antiCDAGWL antibody reacts with a peptide sequence present in both G1 and G2. The Lec-7 antibody recognizes a segment found in the G3 domain. B is a schematic drawing of a chondroitin sulfate chain attached to a serine residue (Ser) in the core protein. The filled circles-open circles-open circles-open squares sequence represents the tetrasaccharide xylose-galactosegalactose-uronic acid linkage. The filled square/open square symbols represent the repeating disaccharides $(\triangle \mathrm{Di} 4 \mathrm{~S}, \triangle \mathrm{Di} \mathrm{6S}$ or $\triangle$ DiOS) and the dotted circle corresponds to the non-reducing terminal (GalNAc4S; GalNAc4,6S; Di4S or Di6S). domains, is a proteolytically sensitive region of the molecule, centrally involved in aggrecan catabolism (10-14). The G2 domain (15) consists of two subdomains also present in G1. The function of G2 is still unclear. The two GAG substitution domains correspond to a KS-rich region with about 50 chains (16), and a CS-rich region with about 100 chains (17). The G3 domain consists of EGFlike, lectin-like (18) and CRP-like motifs, which also occur together in some cell adhesion molecules (19).

We have studied the bullfrog epiphyseal cartilage and reported that it differs from its mammalian counterpart by lacking a columnar arrangement of the chondrocytes in the growth cartilage. Chondrocyte hypertrophy is not associated with matrix calcification or endochondral ossification. Moreover, there is no secondary center of ossification (20).

This led us to believe that the identification and characterization of the macromolecules in the bullfrog epiphyseal cartilage would be important for the understanding of the physiology of this tissue at the cellular and molecular levels.

Since aggrecan function is essential to the physiology and structure of cartilage, we used immunochemical tests to elucidate some of the characteristics of the core protein and biochemical assays to determine some aspects of the attached GAGs. Considering

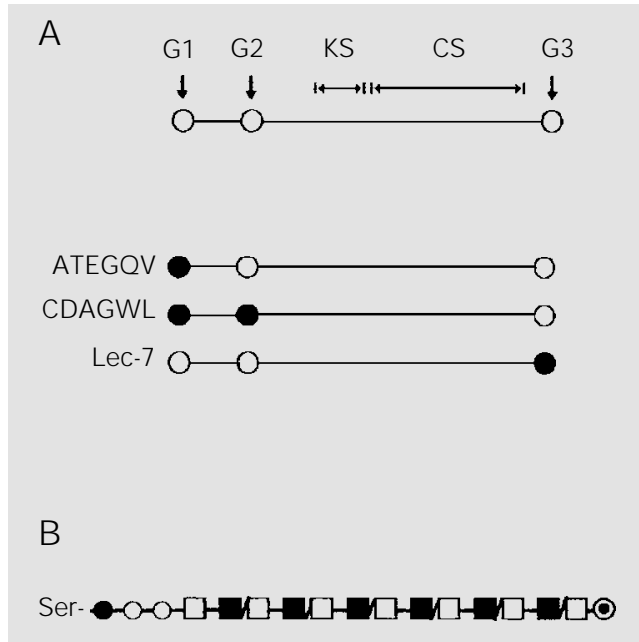

that amphibians are lower vertebrates, the results presented here demonstrate a high conservation of the domain structure of aggrecan.

\section{Material and Methods}

\section{Preparation of the large proteoglycan from the bullfrog femoral distal epiphyseal cartilage}

One-year-old bullfrogs, Rana catesbeia$n a$, were purchased from a farm in Atibaia (SP, Brazil). The femoral distal epiphyseal cartilages were dissected out and the proteoglycans were extracted with $4 \mathrm{M}$ guanidine$\mathrm{HCl}$ in the presence of protease inhibitors and then dialyzed against $0.4 \mathrm{M}$ guanidine$\mathrm{HCl}$ to attain associative conditions before associative cesium chloride gradient centrifugation (21). The high buoyant density fraction $(1.70 \mathrm{mg} / \mathrm{ml}, \mathrm{A} 1$ fraction) was centrifuged again under dissociative conditions to obtain A1D1 fractions. A1D1 fractions were sequentially dialyzed against $1 \mathrm{M} \mathrm{NaCl}$ and water prior to subsequent analyses.

\section{Hydrodynamic size of proteoglycan monomers}

Proteoglycans $(300 \mu \mathrm{g})$ were dialyzed against $0.5 \mathrm{M}$ sodium acetate, $\mathrm{pH} 8.0$, and subjected to gel filtration on a Sepharose CL2B column $(0.5 \times 110 \mathrm{~cm})$ eluted with the same solution at a flow rate of $0.5 \mathrm{ml} / \mathrm{h}$. Fractions $(1 \mathrm{ml})$ were assayed for sulfated GAG content by the dimethylmethylene blue (DMMB) procedure (22).

\section{Isolation of CS chains and Superose 6 chromatography}

Large proteoglycans were subjected to $\beta$ elimination and reduction for $24 \mathrm{~h}$ at $45^{\circ} \mathrm{C}$ in $1 \mathrm{M}$ sodium borohydride in $50 \mathrm{mM} \mathrm{NaOH}$, neutralized with acetic acid on ice, and vacuum dried after the addition of an equal 
volume of methanol (23). The residues were washed three times with $500 \mu 1$ of methanol to remove borate salts, dissolved in $500 \mu \mathrm{l}$ of $4 \mathrm{M}$ guanidine- $\mathrm{HCl}$ in $50 \mathrm{mM}$ acetate buffer, $\mathrm{pH}$ 6.0, and subjected to chromatography on Superose $6(1 \times 24 \mathrm{~cm})$ (Pharmacia, Uppsala, Sweden). The column was eluted with the same solution at a flow rate of $0.5 \mathrm{ml} / \mathrm{min}$. Fractions $(0.5 \mathrm{ml})$ were collected and assayed for sulfated GAG content by the DMMB assay (22).

\section{Fluorescent derivatization of chondroitinase digestion products with 2 -aminopyridine}

The large proteoglycans from the A1D1 fraction (10 $\mu \mathrm{g}$ of sulfated GAGs) were digested with $5 \mathrm{mU}$ of chondroitinase ABC (Seikagaku America, Falmouth, MA, USA) in $50 \mu 1$ of $100 \mathrm{mM}$ ammonium acetate, $\mathrm{pH}$ 7.4 , for $2 \mathrm{~h}$ at $37^{\circ} \mathrm{C}$. Released products were collected into the filtrate of prewashed MicroCon 3 filters. Ammonium acetate was removed in vacuo. The residue was dissolved in $500 \mu \mathrm{l}$ of water and redried. Digestion products were derivatized with 2aminopyridine (AP) (23). AP was freshly prepared before use by adding $500 \mathrm{mg}$ to 100 $\mu 1$ of glacial acetic acid, which had been heated to and maintained at $65^{\circ} \mathrm{C}$, with repeated vortexing until it was completely dissolved. This reagent $(20 \mu \mathrm{l})$ was added to 20 $100 \mathrm{nmol}$ of the chondroitinase digestion products. After incubation of the mixture for $24 \mathrm{~h}$ at $37^{\circ} \mathrm{C}, 5 \mu \mathrm{l}$ of $6 \mathrm{M}$ borane dimethylamine in glacial acetic acid was added and allowed to stand overnight at $37^{\circ} \mathrm{C}$. Acid was removed by speed-vac evaporation and samples were stored at $-20^{\circ} \mathrm{C}$ until the time for analysis. Mono- and disaccharide standards were also subjected to the chondroitinase digestion procedure before fluorescent derivatization. AP-derivatized unsaturated disaccharides were decomposed by treatment with $120 \mu 1$ of $35 \mathrm{mM}$ mercuric acetate, $\mathrm{pH}$ 5.0. Mercuric ions were removed in vacuo before chromatography.

\section{HPLC separation of AP-derivatized chondroitinase digestion products}

AP derivatives (23) were dissolved in $100 \mu \mathrm{l}$ of water and passed over a $100 \mu \mathrm{l}$ bed volume of Dowex $\mathrm{H}^{+}$(BioRad Laboratories, Richmond, CA, USA) immediately before loading onto an AS4A Ion Pac column equilibrated with $1 \mathrm{mM}$ sodium trifluoroacetate, pH 7.0, in a Dionex AI-450 HPLC system. Samples were eluted at a flow rate of $1 \mathrm{ml} /$ min with a step gradient of trifluoroacetate (10 mM, 6 min; 10-50 mM, 4 min; 50-150 mM, 17 min; 150-250 mM, 13 min; 250-500 $\mathrm{mM}, 10 \mathrm{~min}$ ). The eluant was monitored by fluorescent detection with an excitation wavelength of $310 \mathrm{~nm}$ and emission wavelength of $410 \mathrm{~nm}$, using an in-line fluorimeter (Shimadzu Corporation, Tokyo, Japan).

\section{Identification of KS and characterization of the KS-rich region}

The large proteoglycans $(1.0 \mathrm{mg}$ of sulfated GAGs) were loaded onto a Sepharose CL6B column (Pharmacia) $(0.6 \times 120 \mathrm{~cm})$ and eluted with $4 \mathrm{M}$ guanidine- $\mathrm{HCl}$ in 50 mM sodium acetate, $\mathrm{pH} 6.0$, at a flow rate of $5 \mathrm{ml} / \mathrm{h}$. The peak eluted in the void volume of the column was digested with chondroitinase ABC (Seikagaku America) (24) (10 $\mathrm{mU} / \mathrm{mg}$ of sulfated GAG), subjected to SDSPAGE on a $3-16 \%$ gradient gel (25) and assayed by Western blotting with the monoclonal antibodies MST1 (produced by immunization with the large proteoglycan from the hammerhead shark cartilage; non-diluted culture medium) (26) and 4-A-4 (1:1000) (27) against KS, as described below. Another gel was run under the same conditions and stained with $0.25 \%$ Alcian blue in $3 \%$ acetic acid. For the isolation of the KS-rich region, the large proteoglycan $(7.5 \mathrm{mg}$ of sulfated GAG) was digested with chondroitinase $\mathrm{ABC}(10 \mathrm{mU} / \mathrm{mg})$ in $0.1 \mathrm{M}$ Tris-acetate buffer, $\mathrm{pH} 7.3$, for $18 \mathrm{~h}$ at $37^{\circ} \mathrm{C}$. The chondroitinase-treated product was subse- 
quently digested with trypsin and then with chymotrypsin (Sigma Chemical Co., St. Louis, MO, USA) at concentrations of $2 \mu \mathrm{g}$ enzyme/mg of the initial sulfated GAG, for $10 \mathrm{~h}$ at $37^{\circ} \mathrm{C}$ in the same buffer. The material was then chromatographed on a Sepharose CL6B column $(0.6 \times 120 \mathrm{~cm})$ in $0.5 \mathrm{M}$ sodium acetate, $\mathrm{pH} 7.0$, and eluted at a flow rate of $5 \mathrm{ml} / \mathrm{h}$ as previously described by Heinegård and Axelsson (28). A peak containing material that showed metachromasy with DMMB and was devoid of uronic acid (as detected by the orcinol reaction) (29) was found. Fractions of this peak were pooled and electrophoresed on 3-16\% gradient SDSPAGE for $3 \mathrm{~h}$ at $25 \mathrm{~mA}$, with or without prior digestion with keratanase (Seikagaku America). The gel was stained with Alcian blue as described above.

\section{Deglycosylation, SD S-PAGE and Western blotting of the core protein}

A1D1 fractions were deglycosylated by sequential treatment with chondroitinase ABC (proteinase free; Seikagaku America), keratanase II (Seikagaku America; $0.7 \mathrm{mU} /$ $100 \mu \mathrm{g}$ of sulfated GAG) and endo- $\beta$-glycosidase (Seikagaku America; $0.7 \mathrm{mU} / 100$ $\mu \mathrm{g}$ of sulfated GAG). Thirty micrograms of the initial sulfated GAGs were subjected to SDS-PAGE on precast $4-12 \%$ gels (Novex, San Diego, CA, USA) for $90 \mathrm{~min}$ at $125 \mathrm{~V}$

Figure 2 - Hydrodynamic size of large proteoglycan monomers. Gel filtration of proteoglycan monomers present in A1D1 fractions of the ultracentrifugation. The material present in A1D1 fractions was dialyzed against $0.5 \mathrm{M}$ sodium acetate, $\mathrm{pH}$ 8.0, and loaded onto a Sepharose CL2B column $(0.6 \times 120 \mathrm{~cm})$. Fractions $(0.5 \mathrm{ml})$ were assayed for the amount of glycosaminoglycans by the DMMB procedure.
(24). The material was electrotransferred onto nitrocellulose using an XCELL transfer unit (Novex) (30). Membranes were blocked with $5 \%(\mathrm{w} / \mathrm{v})$ skim milk powder in Tris-buffered saline (0.5 M NaCl and $20 \mathrm{mM}$ Tris, $\mathrm{pH} 7.5)$, containing $0.1 \%$ Tween 20 (TST), for $1 \mathrm{~h}$ at room temperature. The polyclonal antibodies used were anti-ATEGQV (1:5000) (which reacts with the IgG loop of the G1 domain of the aggrecan; Kenagy A, Wight $T$ and Sandy JD, unpublished results), anti-CDAGWL (1:3000) (which detects the protein tandem repeat loops of the G1 domain, obtained from Dr. Steve S. Carlson, University of Washington, Seattle, WA, USA) and Lec-7 (raised against a peptide contained in the lectin-like motif of the G3 domain, obtained from Dr. Kurt Doege, Shriners Hospital for Children, Portland, OR, USA) (1:5000) polyclonal antibodies (Figure 1). The anti-chondroitin 4-sulfate (C4S) stub (2B6 clone, 1:750) (31) and anti-chondroitin 6-sulfate (C6S) stub (3B3 clone, 1:5000) (32) monoclonal antibodies and the peroxidase-conjugated secondary antibody (1:5000) were all diluted in $1 \%(\mathrm{w} / \mathrm{v})$ milk powder in TST. Immunoreactivity was developed using the ECL detection kit (Amersham Corporation, Arlington Heights, IL, USA) and exposure to Hyperfilm (Amersham). Rat chondrosarcoma aggrecan (13) was included for comparison.

\section{Results}

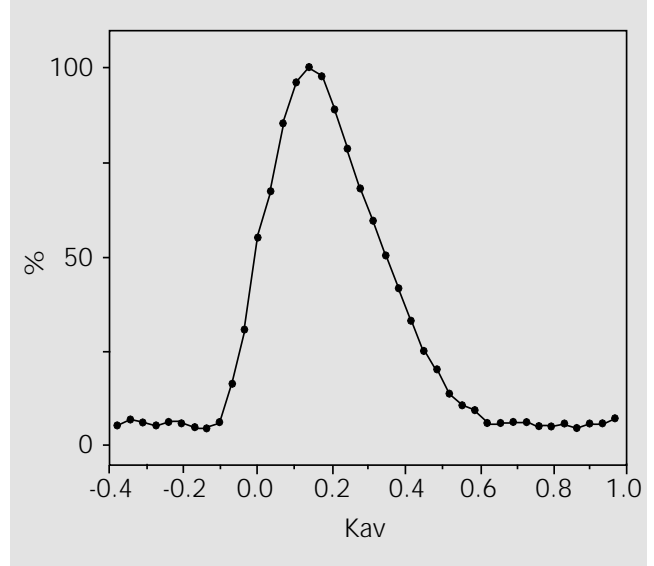

\section{The hydrodynamic size of the proteoglycan monomer and of the CS chains}

Figure 2 shows the chromatographs obtained for the proteoglycan monomers extracted from the bullfrog epiphyseal cartilage by gel filtration on Sepharose CL2B. Kav was 0.14 and Kav range $(50 \%$ of the peak) was 0 to 0.34 . Glycosaminoglycan chains released by $\beta$-elimination of the proteoglycans present in the A1D1 fraction were chromatographed on Superose 6 gel. The 
chains eluted as a single peak with $\mathrm{Kav}=$ 0.40 (Figure 3).

\section{Fluorescent HPLC analysis of chondroitinase ABC digests}

AP-derivatized chondroitinase digestion products were submitted to ion-exchange HPLC analysis with measurement of all internal disaccharides and non-reducing terminals (33). Most of the fluorescent products present in the digests were sulfated $\Delta$ disaccharides $(\Delta \mathrm{Di}$, unsaturated disaccharide) $(97.4 \%)$ (Figure $4 \mathrm{~A}$ and Table 1$)$. The $\triangle \mathrm{Di} 4 \mathrm{~S}: \Delta \mathrm{Di} \mathrm{S}$ ratio was 1.6. GalNAc4S, GalNAc4,6S and the saturated disaccharides GlcA-GalNAc4S (Di4S) and Glc-GalNAc6S (Di6S) were identified as the non-reducing termini of the CS chains (Figure 4) and corresponded to $2.6 \%$ of the total chondroi- tinase digestion products. The average number of repeating disaccharides per chain was estimated by the ratio of interior $\Delta \mathrm{Di}$ to nonreducing termini (Table 1). The analyses also showed that sulfated GalNAc residues were the most abundant termini in the bullfrog CS chain, representing $96 \%$ of the total non-reducing termini (Figure 4B and Table 1)

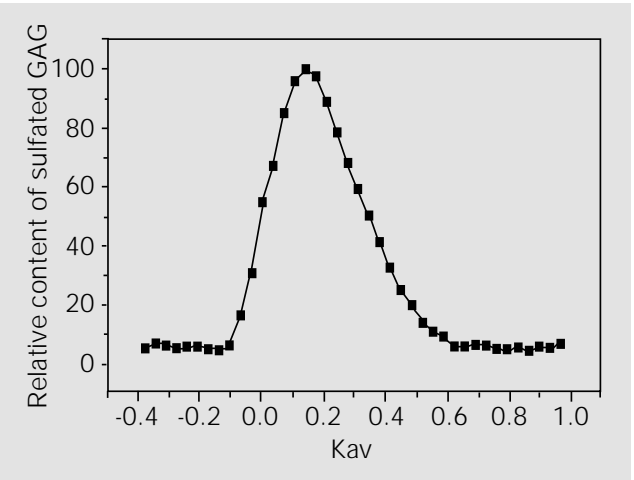

Figure 3 - Hydrodynamic size of large proteoglycan chondroitin sulfate. A $250-\mu \mathrm{g}$ aliquot of large proteoglycans was treated with sodium borohydrate and $\mathrm{NaOH}$ to release the composing glycosaminoglycan (GAG) chains. The released GAGs were chromatographed on Superose 6 and fractions were assayed for sulfated GAGs with DMMB.

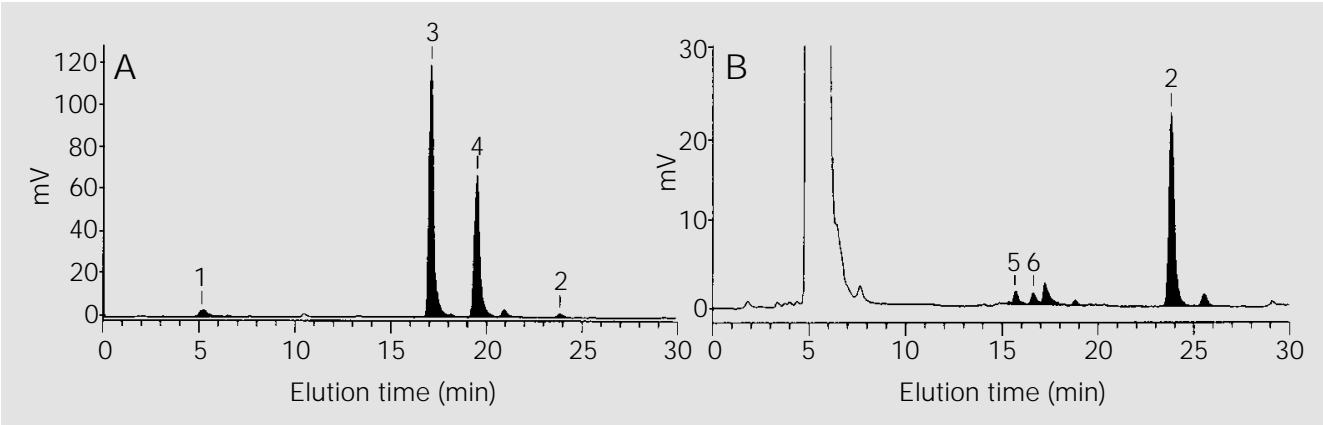

Figure 4 - AS4A ion chromatography-derivatized products from a chondroitinase-digested large proteoglycan. A and $B$, The samples were digested with chondroitinase $A B C$ and derivatized, and portions (200 ng) were chromatographed by AS4A HPLC. Column effluents were monitored for fluorescence (B). Other portions of derivatized products were treated with mercuric acetate prior to HPLC fractionation and monitoring. 2Aminopyridine-derivatized (AP) products were identified by comparison of their elution times relative to standards (1, GalNAc4S-AP; 2, GalNAc4,6S-AP; 3, $\triangle$ Di4S-AP; 4, $\triangle$ Di6S-AP; 5, Di4S-AP; Di6S-AP).

\begin{tabular}{|c|c|c|c|c|c|c|}
\hline \multirow[t]{2}{*}{$\Delta \mathrm{Di} 4 \mathrm{~S} / \Delta \mathrm{Di} \mathrm{i} \mathrm{S}$} & \multirow{2}{*}{$\begin{array}{c}\text { Total } \\
\text { terminalsa }\end{array}$} & \multicolumn{4}{|c|}{ Non-reducing terminals } & \multirow{2}{*}{$\begin{array}{c}\text { CS chain } \\
\text { size }^{b}\end{array}$} \\
\hline & & GalNAc4S & GalNAc4,6S & Di4S & Di6s & \\
\hline 1.6 & $0.49(2.6 \%)$ & $0.29(59 \%)$ & $0.18(37 \%)$ & $0.01(2 \%)$ & $0.01(2 \%)$ & $\sim 38$ \\
\hline
\end{tabular}


in the form of GalNAc4S and GalNAc4,6S, which corresponded to 59 and $37 \%$, respectively. Both Di4S and Di6S termini were present in equal amounts (2\% each of the total) (Figure 4B and Table 1), and hence 4\% of the CS chains terminated as GlcA.

\section{Identification of KS and characterization of the KS-rich region}

The initial guanidine- $\mathrm{HCl}$ extract was chromatographed on Sepharose CL6B (Figure $5 \mathrm{~A}$ ). The peak eluted at the void volume was treated with chondroitinase ABC. The digestion products were electrophoresed by SDS-PAGE. Components with high relative molecular mass were developed after staining with Alcian blue. The non-digested proteoglycan was in the stacking gel and the chondroitinase $\mathrm{ABC}$-treated proteoglycan migrated as a high molecular mass component at the top of the separating gel (Figure
5B). Other samples were electroblotted onto nitrocellulose membranes and incubated with the monoclonal antibody MST1 (Figure 5C) or 4-A-4 (Figure 4D). Immunoreactivity for both MST1 and 4-A-4 was found in high molecular mass components only after chondroitinase digestion. Non-digested proteoglycans did not react with either monoclonal antibody. To isolate the KS-rich region, the monomers of A1D1 were digested first with chondroitinase $\mathrm{ABC}$ and then with a trypsin/ chymotrypsin combination. The digestion products were chromatographed on a Sepharose CL6B column (Figure 6A). The peak detected by metachromasy with DMMB was devoid of uronic acid, as detected by the orcinol reaction. This product migrated as a polydisperse band centered at $110 \mathrm{kDa}$ in a 3-16\% gradient SDS-PAGE, after Alcian blue staining (Figure 6B). This Alcian blue-positive band was digested by keratanase II (Figure $6 \mathrm{~B}$ ).
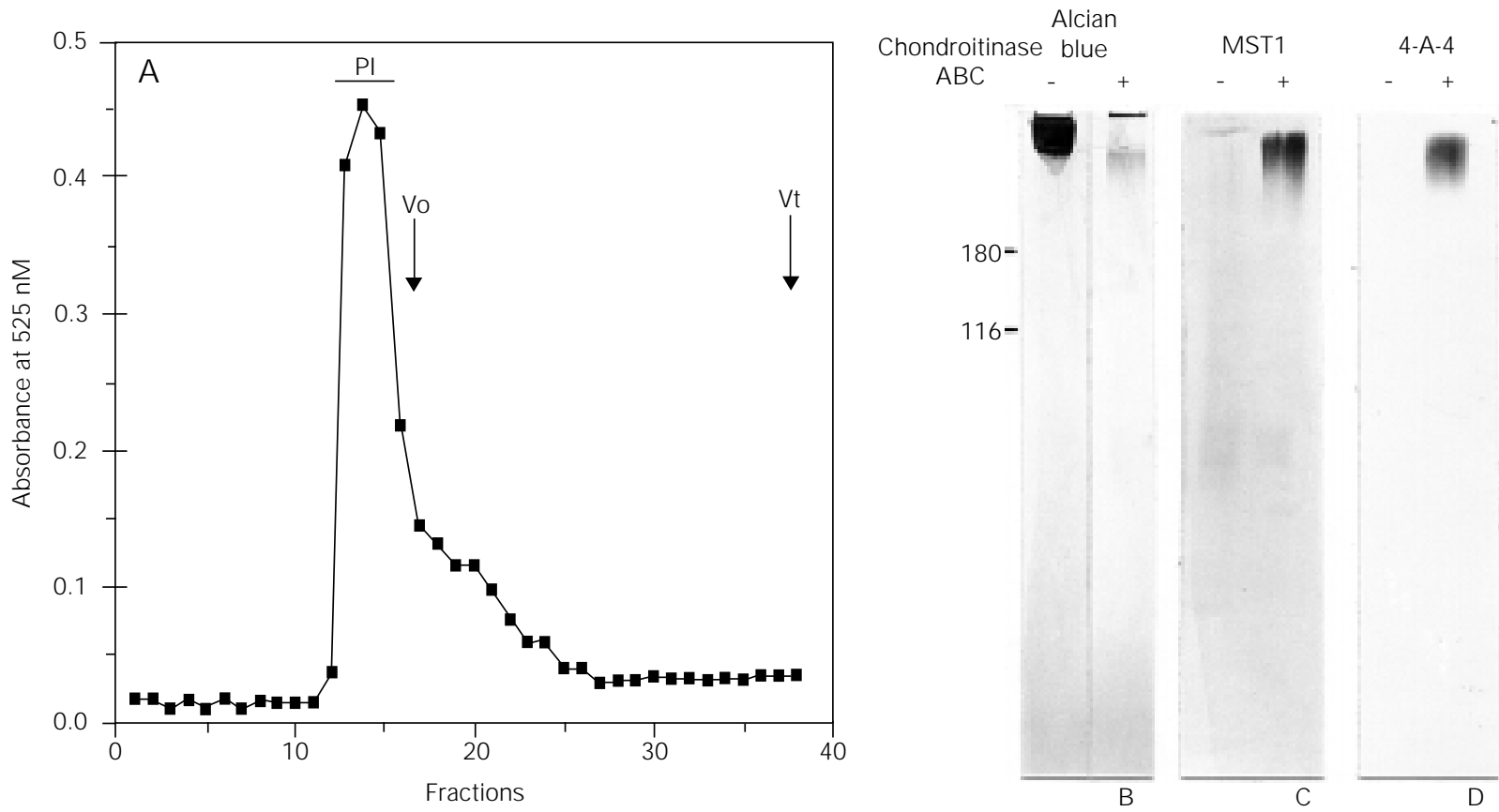

Figure 5 - Identification of keratan sulfate in large proteoglycans. A, Chromatography on Sepharose CL6B of large proteoglycan total extracts. PI, Peak eluted in the void volume. B, SDS-PAGE plus Alcian blue staining of the large proteoglycans present in PI. The large proteoglycan found in the stacking gel was digested by chondroitinase $A B C$ and was retained at the top of the separating gel. C and $D$, Immunochemical identification of keratan sulfate in large proteoglycans using the MST1 and 4-A-4 monoclonal antibodies, respectively. Vo, Void volume; Vt, total volume. 


\section{Identification of G 1/G2, G3, C4S stubs and C6S stubs in a large proteoglycan}

The reactivity of the large proteoglycan core protein to anti-ATEGQV, anti-CDAGWL, anti-Lec-7, anti-C4S stubs (2B6) and anti-C6S stubs (3B3) was examined by Western blot analysis. The anti-ATEGQV antibody reacted with a single band at about $300 \mathrm{kDa}$ in the A1D1 fraction (Figure 7A, lane 4) and with fast moving species in A1 fractions (Figure $7 \mathrm{~A}$, lane 3). The anti-CDAGWL detected at least five species with molecular mass between 130 and $300 \mathrm{kDa}$ in the $\mathrm{A} 1$ fractions (Figure 7B, lane 3). The A1D1 fraction presented the same molecular species in different amounts and a further 250-kDa band, besides the $300-\mathrm{kDa}$ full core protein. A variety of molecular species reactive to the Lec-7 antibody was found in the A1 fraction. The 300$\mathrm{kDa}$ component showed strong immunoreactivity to this antibody (Figure 7C, lanes 3 and 4). Immunoreactivity to the $3 \mathrm{~B} 3$ and $2 \mathrm{~B} 6$ monoclonal antibodies was shown for many bands in the A1 and A1D1 fractions obtained by ultracentrifugation. Three main species of 60 , 75 and $100 \mathrm{kDa}$ were found in the A1 fraction (lane 3 in Figure 7D and E). Other bands in the
A1 and A1D1 fractions migrated between 130 and $250 \mathrm{kDa}$ (Figure 7D and E, lanes 3 and 4). The $300-\mathrm{kDa}$ band also showed reactivity to these two antibodies.

\section{Discussion}

The bullfrog epiphyseal cartilage shows a unique morphology and has a distinctive role in long bone growth, as compared to the mammalian and avian models (19). We used immunochemical and biochemical assays for the identification of structural and compositional characteristics of the large proteoglycan found in the bullfrog epiphyseal cartilage, as compared to the classical model for aggrecan.

Chondroitin sulfate chains were isolated and shown to be about 38 disaccharides long and to have $\Delta \mathrm{Di} 4 \mathrm{~S}$ as the predominant form of sulfation $(\Delta \mathrm{Di} 4 \mathrm{~S}: \Delta \mathrm{Di} 6 \mathrm{~S}=1.6)$. Considering the number of internal disaccharides, the tetrasaccharide linkage and $300 \mathrm{Da}$ as the mean molecular mass for the non-reducing terminal $(23,34)$, it appears that the CS chains in the young adult bullfrog epiphyseal cartilage have a molecular mass of about 19,524 Da.

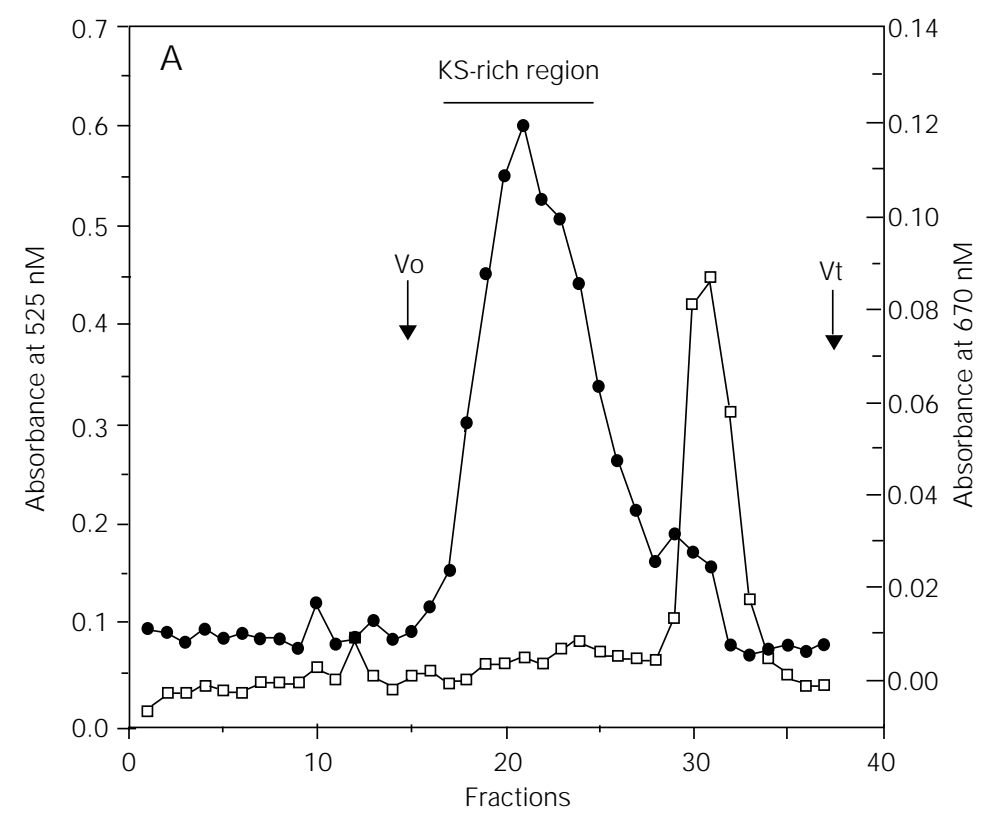

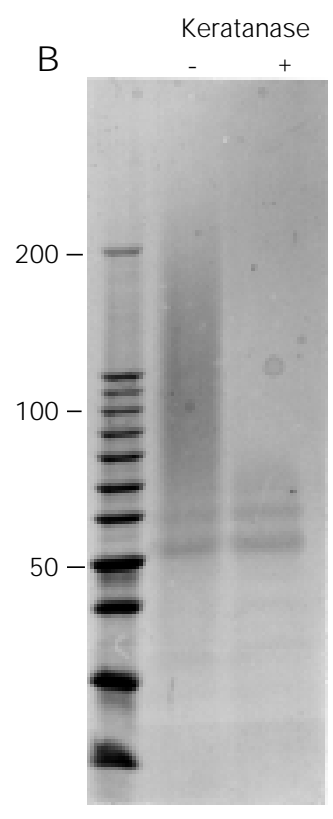

Figure 6 - Characterization of the keratan sulfate (KS)-rich region in large proteoglycans. A, Sepharose CL6B of the products obtained by sequential treatment with chondroitinase $A B C$, trypsin and chymotrypsin. A KS-rich region was identified by the presence of sulfated glycosaminoglycan (DMMB reaction A525 - circles) and the lack of reaction for uronic acid (orcinol reaction - A670 - squares). B, SDS-PAGE of the material present in the peak corresponding to the KS-rich region prior to and after keratanase digestion. Keratanase treatment eliminates the polydisperse band with a molecular mass centered at 110 $\mathrm{kDa}$. Alcian blue staining. Vo, Void volume; Vt, total volume. 
Figure 7 - Western blot of $\mathrm{Al}$ and A1D1 proteoglycans with the anti-ATEGQV (A), antiCDAGWL (B), LeC-7 (C), $3 B 3$ (D) and 2B6 (E) antibodies. Al (lanes 3) and A1D1 (lanes 4) extracts were deglycosylated, electrophoresed on $4-12 \%$ gradient gels and blotted onto nitrocellulose for the reaction with the different antibodies. Lanes 1, Molecular mass markers. Lanes 2, Rat chondrosarcoma aggrecan.
Since $\Delta$ Di0S was not detected by the HPLC procedure employed in the present study, it is possible that these chains are longer. However, the presence of nonsulfated disaccharides needs to be confirmed by complementary methodology.

These structural characteristics of the CS chains correspond to those found in young human aggrecan, with respect to the chain length, and to the aged human aggrecan, with respect to the structure of the nonreducing terminal, considering the presence of GalNAc4,6S, which is only found in older individuals (33). It is worth mentioning that GalNAc4S is the only form of GalNAc at the non-reducing terminal of CS in the newborn
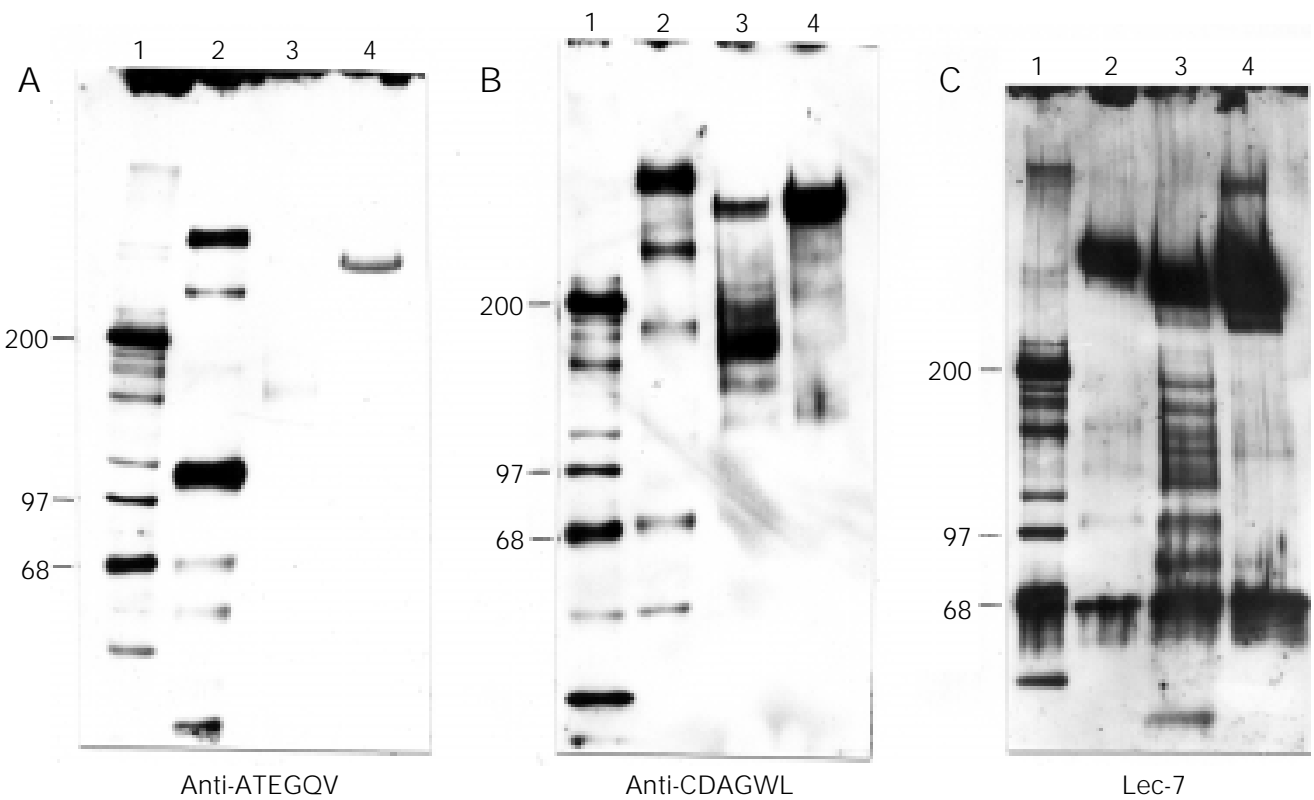

Lec-7

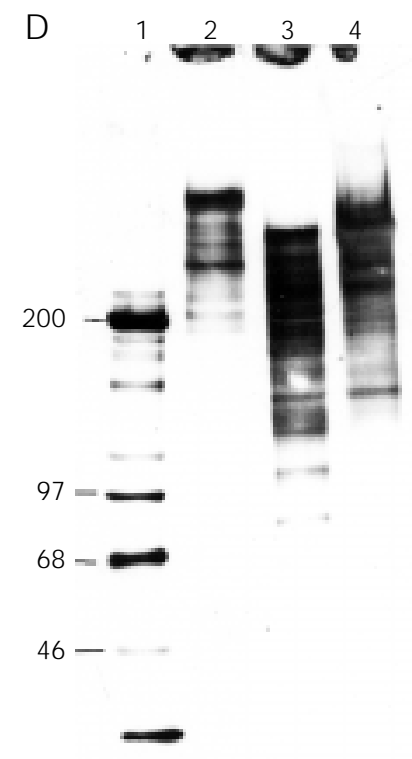

3B3

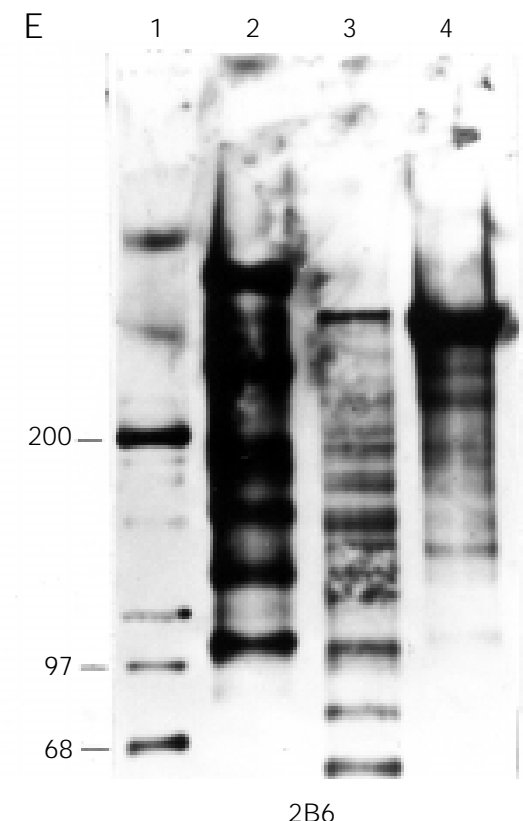


and young human aggrecan (33).

Keratan sulfate was also identified as a component of the bullfrog large proteoglycan using two monoclonal antibodies (4-A-4 and MST1 clones) on Western blots. Antibody reactivity is hindered by the presence of the CS chains, as indicated by the fact that the reaction with either antibody is only achieved after chondroitinase treatment. The isolation of a KS-rich region suggests further similarity with the mammalian aggrecan. We have shown by SDS-PAGE that the KS-rich region is about $110 \mathrm{kDa}$. This is really close to the $122 \mathrm{kDa}$ determined for the KS-rich region of the bovine aggrecan (28). Though it is well known that KS concentrates in a KS-rich region after the G2 domain and before the CS substitution region in all aggrecan molecules already described, except for the rat chondrosarcoma aggrecan, which lacks this KS-rich region $(35,36)$, its exact location in the bullfrog molecule still needs to be determined.

The use of different antibodies has revealed important aspects of the large proteoglycan structure. The 2B6 and 3B3 antibodies, besides showing the existence of $\mathrm{C} 4 \mathrm{~S}$ and $\mathrm{C} 6 \mathrm{~S}$ stubs in the core protein after chondroitinase digestion, also revealed that the deglycosylated full core protein is about 300 $\mathrm{kDa}$. On the other hand, the positive reactions to the anti-ATEGQV and Lec-7 antibodies are strong evidence for the existence of G1 and G3 domains. Though CDAGWL is a sequence found in G2, it is also present in G1 and, as such, cannot be used as an indicator of the existence of this globular domain. However, transmission electron microscopy of rotary shadowed isolated molecules has demonstrated morphologically the existence of the G2 domain besides G1 and G3 (Covizi DZ, Keene DR, Plaas AHK, Sandy JD and Carvalho HF, unpublished results).

The presence of molecular species with molecular mass below $300 \mathrm{kDa}$ may represent degradation products containing the globular domains (11-14). Whether they represent normal catabolic products of the aggrecan remains to be ascertained. Since protease inhibitors were added to the extracting buffer, we do not consider the possibility of artifactual degradation of the proteoglycan monomer during extraction.

The characteristics of the large proteoglycan of the bullfrog epiphyseal cartilage described in this paper permit us to suggest that it is aggrecan. Furthermore, they also reveal a high conservation of its domain structure and glycosaminoglycan substitution and that the unique characteristics of the bullfrog epiphyseal cartilage are not attributable to differences in its aggrecan structure.

\section{Acknowledgments}

Parts of this work were developed in the Laboratories of Cell Biology and Biochemistry of the Shriners Hospital for Children, Tampa Unit, Tampa, FL, USA. The authors are thankful to Anna H.K. Plaas and John D. Sandy for their hospitality, help and free access to equipment and reagents during D.Z. Covizi's stay in Tampa. The MST1 antibody was a kind donation of Dr. Y. Michelacci.

\section{References}

1. Maroudas A (1979). Physico-chemical properties of articular cartilage. In: Freeman MAR (Editor), Adult Articular Cartilage. 2nd edn. Pitman, Tunbridge Wells, England, 215-290.

2. Hascall VC (1988). Proteoglycans: the chondroitin sulfate/keratan sulfate proteo- glycan of cartilage. ISI Atlas of Science: Biochemistry, 1: 189-198.

3. Heinegård $D \& \&$ Hascall VC (1979). The effects of dansylation and acetylation on the interaction between hyaluronic acid and the hyaluronic acid-binding region of cartilage proteoglycans. J ournal of Biologi- cal Chemistry, 254: 921-926.

4. Heinegård D \& Sommarin $Y$ (1987). Isolation and characterization of proteoglycans. Methods in Enzymology, 144: 319-372.

5. Carney SL \& Muir H (1988). The structure and functions of cartilage proteoglycans. Their functional interdependency. Arthri- 
tis and Rheumatism, 26: 1111-1119.

6. Buckwalter J, Huntikor E, Rosenberg L, Cortts R, Adams M \& Eyre D (1988). Articular cartilage: injury and repair. In: Woo SY \& Buckwalter J (Editors), Injury and Repair of Muscle Skeletal Soft Tissues. American Academy of Orthopaedic Surgeons, Park Ridge, IL, 405-425.

7. Buckwalter JA, Poole AR, Reiner A \& Rosenberg LC (1982). Immunoferritin binding to proteoglycan monomers. An electron microscopic study. Journal of Biological Chemistry, 257: 10529-10532.

8. Hardingham TE \& Muir H (1972). Biosynthesis of proteoglycans in cartilage slices: fractionation by gel chromatography and equilibrium density gradient centrifugation. Biochemical J ournal, 126: 791-803.

9. Hascall VC \& Heinegård D (1974). Aggregation of cartilage proteoglycans. II. Oligosaccharide competitors of the proteoglycan-hyaluronic acid interaction. J ournal of Biological Chemistry, 249: 4242-4249.

10. Sandy JD, Boynton RE \& Flannery CR (1991). Analysis of the catabolism of aggrecan in cartilage explants by quantitation of peptides from the three globular domains. J ournal of Biological Chemistry, 266: 8198-8205.

11. Sandy J D, Neame PJ, Boynton RE \& Flannery CR (1991). Catabolism of aggrecan in cartilage explants. Identification of a major cleavage site within the interglobular domain. J ournal of Biological Chemistry, 266: 8683-8685.

12. Flannery CR, Lark MW \& Sandy J D (1992). Identification of a stromelysin cleavage site within the interglobular domain of human aggrecan. Evidence for proteolysis at this site in vivo in human articular cartilage. J ournal of Biological Chemistry, 267: 1008-1014.

13. Lark MW, Gordy J T, Weidner J R, Avala J, Kimura J H, Williams HR, Mumford RA, Flannery CR, Carlson SS, Iwata M \& Sandy JD (1995). Cell-mediated catabolism of aggrecan: Evidence that cleavage at the "aggrecanase" site (Glu 373-Ala 374) is a primary event in proteolysis of the interglobular domain. J ournal of Biological Chemistry, 270: 2550-2556.

14. Arner EC, Pratta MA, Decicco CP, Xue CB, Newton RC, Trzaskos J M, Magolda RL \& Tortorella MD (1999). Aggrecanase. A target for the design of inhibitors of cartilage degradation. Annals of the New York Academy of Sciences, 878: 92-107.

15. Fosang AJ \& Hardingham TE (1989). Isolation of the N-terminal globular protein domains from cartilage proteoglycans.
Biochemical J ournal, 261: 801-809.

16. Antonsson $P$, Heinegård $D \&$ Oldberg $A$ (1989). The keratan sulfate-enriched region of bovine cartilage proteoglycan consists of a consecutively repeated hexapeptide motif. J ournal of Biological Chemistry, 264: 16170-16173.

17. Paulsson $M$, Morgelin $M$, Wiedemann $H$, Beardmore-Gray M, Dunham D, Hardingham TE, Heinegård $D$, Timpl $R \&$ Engel J (1987). Extended and globular protein domains in cartilage proteoglycans. Biochemical J ournal, 245: 763-772.

18. Halberg DF, ProulX G, Doege $K$, Yamada $Y$ \& Drickamer K (1988). A segment of the cartilage core protein has lectin-like activity. J ournal of Biological Chemistry, 263: 9486-9490.

19. Flannery $C R$, Stanescu $V$, Morgelin $M$, Boynton R, Gordy J \& Sandy J D (1992). Variability in the $\mathrm{G} 3$ domain content of bovine aggrecan from cartilage extracts and chondrocyte cultures. Archives of Biochemistry and Biophysics, 297: 52-60.

20. Felisbino SL \& Carvalho HF (1999). The epiphyseal cartilage and growth of long bones in Rana catesbeiana. Tissue and Cell, 31: 301-307.

21. Heinegård D (1972). Extraction, fractionation and characterization of proteoglycans from bovine tracheal cartilage. Biochimica et Biophysica Acta, 285: 181-192.

22. Farndale RW, Buttle DJ \& Barret AJ (1986). An improved quantitation and discrimination of sulfated glycosaminoglycans by use of dimethylmethylene blue. Biochimica et Biophysica Acta, 883: 173177.

23. Plaas AHK, Hascall VC \& Midura RJ (1996). Ion exchange HPLC microanalysis of chondroitin sulfate: quantitative derivatization of chondroitin lyase digestion products with 2-aminopyridine. Glycobiology, 6: 823-829.

24. Shibata S, Midura RJ \& Hascall VC (1992). Structural analysis of the linkage region oligosaccharides and unsaturated disaccharides from chondroitin sulfate using CarboPac PA1. J ournal of Biological Chemistry, 267: 6548-6555.

25. Laemmli UK (1979). Cleavage of structural proteins during the assembly of the head of bacterial phage T4. Nature, 227: 680-685.

26. Alves MLM, Straus AH, Takahashi HK \& Michelacci YM (1995). Monoclonal antibody directed to shark cartilage proteoglycans that recognizes keratan sulfate chains. XXIV Annual Meeting of the Brazilian Society for Biochemistry and M olec- ular Biology, Caxambu, MG, Brazil, May 69, 148 (Abstract).

27. Thonar EJ, Lenz ME, Klintwork GK, Caterson B, Pachman EM, Glickman P, Kartz R, Huff J \& Kuettner KE (1985). Quantification of keratan sulfate in blood as a marker of cartilage catabolism. Arthritis and Rheumatism, 28: 1367-1376.

28. Heinegård D \& Axelsson I (1977). Distribution of keratan sulfate in cartilage proteoglycans. J ournal of Biological Chemistry, 252: 1971-1979.

29. Brown AH (1946). Determination of pentoses in the presence of large quantities of glucose. Archives of Biochemistry and Biophysics, 11: 269-278.

30. Larsson $T$, Sommarin $Y$, Paulsson $M$, Antonsson $P$, Hedbom $E$, Wendel $M$ \& Heinegård $D$ (1991). Cartilage matrix proteins. A basic 36-kDa protein with a restricted distribution to cartilage and bone. J ournal of Biological Chemistry, 266: 20428-20433.

31. Caterson B, Christner JE, Bakert JR \& Couchman J R (1985). Production and characterization of monoclonal antibodies directed against connective tissue proteoglycans. Federation Proceedings, 44: 386393.

32. Caterson B, Mohmoodian F, Sorrell J M, Hardingham TE, Bayliss MT, Carney SL, Ratcliff A \& Muir HM (1990). Modulation of native chondroitin sulfate structure in tissue development and disease. J ournal of Cell Science, 97: 411-417.

33. Plaas AHK, Wong-Palms S, Roughley PJ Midura RJ \& Hascall VC (1997). Chemical and immunological assay of the nonreducing terminal residues of chondroitin sulfate from human aggrecan. J ournal of Biological Chemistry, 272: 20603-20610.

34. Midura RJ, Salustri A, Calabro A, Yanagishita M \& Hascall VC (1994). Highresolution separation of disaccharides and oligosaccharide alditols from chondroitin sulfate, dermatan sulfate and hyaluronan using CarboPac PA1 chromatography. Glycobiology, 4: 333-342.

35. Choi HU, Meyer K \& Swarm R (1971). Mucopolysaccharide and protein-polysaccharide of a transplantable rat chondrosarcoma. Proceedings of the National Academy of Sciences, USA, 68: 877-879.

36. Oegema TR, Hascall VC \& Dziewiatkowski DD (1975). Isolation and characterization of proteoglycans from the Swarm rat chondrosarcoma. J ournal of Biological Chemistry, 250: 6151-6159. 